\title{
Acteniopsis gambronensis sp. n. (Pyralidae: Pyralinae), a new species from Iran, with a revision of the genus Acteniopsis Amsel, 1959
}

\author{
Helen Alipanah $^{1}, \mathrm{~J}_{\text {An }}$ Asselbergs ${ }^{2}$
}

1 Iranian Research Institute of Plant Protection (IRIPP), Agricultural Research, Education and Extension Organization (AREEO),Tehran; e-mail: h.alipanah@areeo.ac.ir; halipanah@gmail.com

2 Neerland 20,4614 GD Bergen op Zoom, The Netherlands; e-mail: jef.asselbergs@hetnet.nl

http://zoobank.org/9258CFDE-5EDD-4881-A3AF-7BD831F29CF1

Received 11 December 2017; accepted 10 January 2018; published: 22 February 2018

Subject Editor: David C. Lees

\begin{abstract}
A complete description of Acteniopsis gambronensis sp. $\mathbf{n}$. is given based on three males and three females collected in the south of Iran, Hormozgan Province. The female of A. kurdistanella Amsel, 1959 is redescribed and illustrated and new distributional data for this species is also provided. Acteniopsis robustus Asselberges, 2010 is transferred to the genus Stemmatophora Guenée, 1854, S. robustus (Asselbergs, 2010), comb. n. A taxonomic review of the genus Acteniopsis is presented.
\end{abstract}

\section{Introduction}

The genus Acteniopsis Amsel, 1959 was erected to accommodate the type species A. kurdistanella Amsel, 1959. Acteniopsis belongs to the subfamily Pyralinae along with more than 1100 species in 134 genera. This subfamily is more diverse in Asia and Africa than in the western hemisphere (Munroe and Solis 1999; Nuss et al. 2003-2017). There is no obvious synapomorphic character for this subfamily (Solis and Shaffer 1999).

Prior to the current study, Acteniopsis included only two species, A. kurdistanella and A. robustus Asselbergs, 2010 which had been described from Iraq and United Arab Emirates, respectively. The former species is also reported from Iran by Amsel (1961). According to Amsel (1959), this genus is generally close to Actenia Guenée, 1854 (presently known as Stemmatophora Guenée, 1854), although has very small and hardly recognizable maxillary palpi, and different, much shorter, and more broadly scaled labial palpi. The wing venation of these two genera is more or less similar accordingly; however in the hindwing of Acteniopsis the veins $\mathrm{M}_{2}$ and $\mathrm{M}_{3}$ originate from the same point, while in Stemmatophora they are on a short stalk. Also, in the forewing of Stemmatophora vein $\mathrm{R}_{5}$ is more or less on a long stalk at $\mathrm{R}_{3}+\mathrm{R}_{4}$, while in Acteniopsis $\mathrm{R}_{3}+\mathrm{R}_{4}+\mathrm{R}_{5}$ arising from a common point, and sometimes in female, $\mathrm{R}_{3}+\mathrm{R}_{4}$ has a short stalk with $\mathrm{R}_{5}$. Their antennae are differently ciliated ventrally: Stemmatophora has two rows of stout brushes of ciliae ending in numerous split hairs, while in Acteniopsis the ciliae are very tender, distally split in few fine hairs (Amsel 1959).

During the study of Pyralinae of Iran, an unknown Acteniopsis species was found in the Lepidoptera collection of the Hayk Mirzayans Insect Museum (HMIM), Iranian Research Institute of Plant Protection (IRIPP). The aim of the present study is to describe this new Acteniopsis species which 
has been collected in Hormozgan Province in 1986. We also redescribe the female of $A$. kurdistanella based on the Iranian specimens collected in Chaharmahal va Bakhtiari, Fars, Hamedan and Kermanshah Provinces. Furthermore, the genus Acteniopsis is here revised.

\section{Methods}

Morphological characters were examined using a stereomicroscope (maximum magnification 128×). Genitalia dissections were based on those described by Clarke (1941) and Robinson (1976). Wings were slide-mounted using the technique proposed by Robinson (1976), except staining denuded wings in eosin overnight. Photographs were taken using a digital Still camera DSC-F717 and a Dino-Eye Microscope Eye-piece camera. The examined specimens of A. gambronensis and A. kurdistanella are deposited at HMIM, and the paratypes of $A$. robustus deposited in the collection of the second author.

\section{Taxonomy}

Stemmatophora robustus (Asselbergs, 2010), comb. n.

Acteniopsis robustus Asselbergs, 2010: 554-555, pl. 1, figs 1-3.

Material examined. Holotype 1 đ̂, United Arab Emirates, Wadi Maidaq, 460 m, 12.IV.2006, leg. C. Gielis, GP. 5787 Asb, in Naturalis Biodiversity Center, Leiden; Paratypes, 1 ô, United Arab Emirates, 10 km. NE. Huwaylat, 18.IV.2006, leg. J. Buszko, GP 6234 Asb, 1 đ̊ same data in Naturalis Biodiversity Center, Leiden. Holotype and Paratypes were examined by the second author.

Diagnosis. Acteniopsis robustus was described by Asselbergs (2010) based on three male specimens. Examination of the types of $A$. robustus revealed that this species is almost similar to $A$. kurdistanella and the newly described species superficially; however, shares a variety of characters with other members of the genus Stemmatophora including: (1) very long maxillary palpi (more than three-fifth of the length of labial palpi and half times the horizontal diameter of compound eye in Paratypes) compared with very small and hardly recognizable maxillary palpi in A. kurdistanella and A. gambronensis; (2) long and relatively slender labial palpi in contrast to shorter and broadly scaled labial palpi of $A$. kurdistanella and A. gambronensis; (3) ciliae at the ventral surface antennae, consist of two pairs of plumose ciliae on each flagellum in A. robustus, while in $A$. kurdistanella and $A$. gambronensis they form a transverse row of at least ten ciliae (Fig. 4C).

There are some other differences between the male genitalia of A. robustus, A. kurdistanella and A. gambronensis:

1) Slender, rod-shaped cornutus of $A$. robustus (Fig. 2F) compared with the stouter and anchor-shaped cornuti of A. kurdistanella and A. gambronensis (Figs 2D, E).

2) In both A. kurdistanella and A. gambronensis the vinculum is basally pointed (Figs 2A, B), while in $A$. robustus it is basally rounded.

3) In A. kurdistanellus and A. gambronensis the gnathos does not exceed the uncus (Fig. 2A) or slightly exceeds it (Fig. 2B), whereas in A. robustus it exceeds clearly.

4) The valva in A. robustus is slightly curved posteriorly, whereas in A. kurdistanella and A. gambronensis it is straight (Figs 2A, B). 
It should be noted that Acteniopsis robustus has the largest wingspan (22-24 mm) compared with A. kurdistanella (17-18 mm) and A. gambronensis (13.7-17.0 mm).

In view of the above, we hereby transfer the species $A$. robustus from Acteniopsis Amsel, 1959 to Stemmatophora Guenée, 1854.

\section{Acteniopsis gambronensis sp. $\mathbf{n}$.}

http://zoobank.org/AD2D16CC-7153-4E2A-87CB-A2334AD7DE17

Material examined. Holotype $\hat{\partial}$, Iran, Hormozgān Prov.: Isin, Geno, 750 m a.s.l., 25.IV.1986, Mirzāyāns, Borumand leg.; Paratypes 2 ㅈํำ 3 우우, same data as the Holotype. Deposited at HMIM, IRIPP, Tehran, Iran (GS: HA-2151, HA-2307, HA-2309).

Diagnosis. Both Acteniopsis gambronensis and A. kurdistanella are similar to each other in wing venation and shape of the maxillary palpi and labial palpi; however their wing pattern is slightly different. In A. gambronensis, the antemedian and postmedian lines are clearly visible, while in $A$. kurdistanella the antemedian line is very weak and sometimes hardly distinguishable. In $A$. kurdistanella the two transverse lines are reddish-brown, but these lines are white in A. gambronensis. The forewing of $A$. kurdistanella is pale clay-coloured, while in A. gambronensis the ground colour is pale-ochreous to yellowish-ochre (Figs 1C, D).

Although these two species are similar in the shape of the male genitalia, there are some differences:

1) In A. gambronensis the phallus is straight and cleaver-shaped (its width in the proximal half is half length of its width in the distal part) (Fig. 2A), while in A. kurdistanella it is slightly curved and is equally wide throughout its length (Fig. 2B).

2) In A. gambronensis the gnathos does not extend to the distal margin of the uncus and is almost straight apically (Fig. 2A), but in A. kurdistanella it reaches the distal margin or is slightly exceeding it with a small hook at the apex (Figs 2B, C).

3) Although as stated by Amsel (1959), in A. kurdistanella the uncus has parallel margins, in all the examined Iranian $A$. kurdistanella specimens, it was slightly constricted basally (Fig. 2B); while in A. gambronensis the width of both proximal and distal ends were the same (Fig. 2A).

4) The longer arm of anchor-shaped cornutus in A. gambronensis is almost finger-shaped (Figs 2A, D), but in A. kurdistanella is tapering to a point (Figs 2B, E).

Examination of the female genitalia of $A$. gambronensis and the newly described genitalia of $A$. kurdistanella reveals that the latter species is very close to A. gambronensis in this regard. The only differences of these two species are as below:

1) In A. gambronensis the ductus bursae is relatively wide and bulbous near the junction with the antrum, with an almost knee-shaped bend (Figs 3A, C), whilst in A. kurdistanella it is slightly narrowed posteriorly at the junction with the antrum, with an upturned bend (Figs 3B, D).

2) In A. gambronensis the folded area of the antrum is clearly extended to the posterior end of ductus bursae (Figs 3A, C), whereas in A. kurdistanella this area is slightly extended to the posterior end of the ductus bursae (Figs 3B, D). 

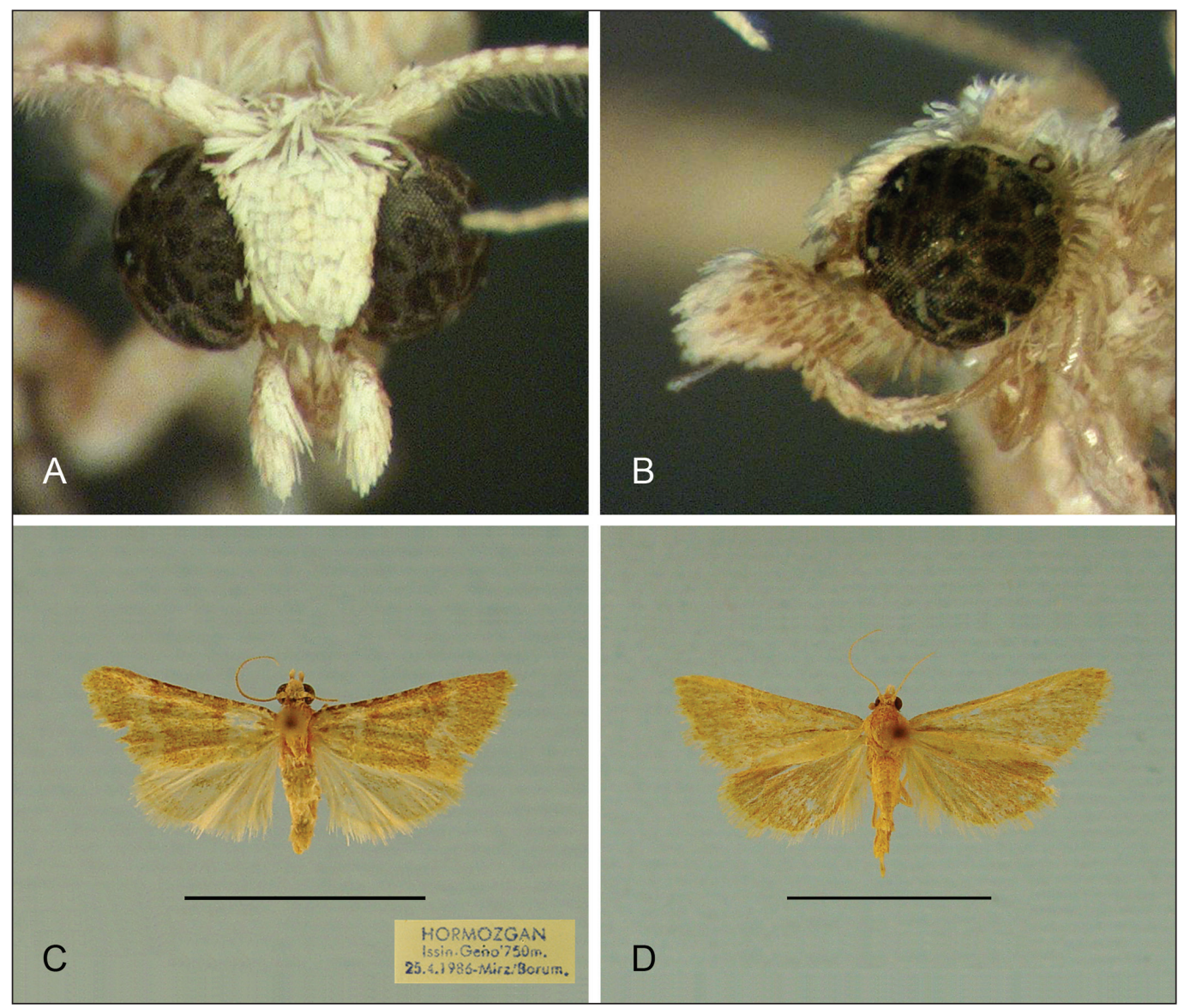

Figure 1. Acteniopsis gambronensis sp. n. head and adult male (A-C), and A. kurdistanella Amsel, adult female (D). A) head in frontal view, B) head in lateral view, C) adult male (Holotype, Iran, Hormozgan Prov., Isin). Scale bars: $1 \mathrm{~cm}$.

Description. Female slightly larger than the male. Forewing length, males $\overline{\mathrm{x}}=6.5 \mathrm{~mm} \pm 0.5$ ( $\mathrm{n}=$ 3), females $\bar{x}=7.1 \mathrm{~mm} \pm 0.56(\mathrm{n}=3)$, Holotype, $6.5 \mathrm{~mm}$.

Head (Figs 1A, B). Chaetosemata and ocelli present; frons smooth; frons and vertex covered with relatively wide, white smooth scales (sometimes tinged with pale yellow scales); occipital area roofed with relatively narrow and slightly appressed white scales; collar covered with relatively wide uniformly yellowish-cream scales; labial palpi porrect with slightly drooping apex, its length 1.45-1.70 times the horizontal diameter of compound eye $(n=6)$, second segment the longest, first segment almost two-thirds of the second one and apical segment very short, slightly more than one-fifth of the second segment. Labial palpi covered with light-ochreous scales tinged with slightly to much darker scales latero-ventrally, except for distal one-fifth (or slightly less than this) which is white dorso-laterally (Fig. 1B), all the segments white internally except for darker ventro-marginal sides; maxillary palpi short (slightly more than one-fifth of the length of labial palpi), covered with pale-ochreous scales laterally; proboscis covered with light ochre to ochreous-creamy scales basally; antennae annulated with alternative light brown and creamy scales 


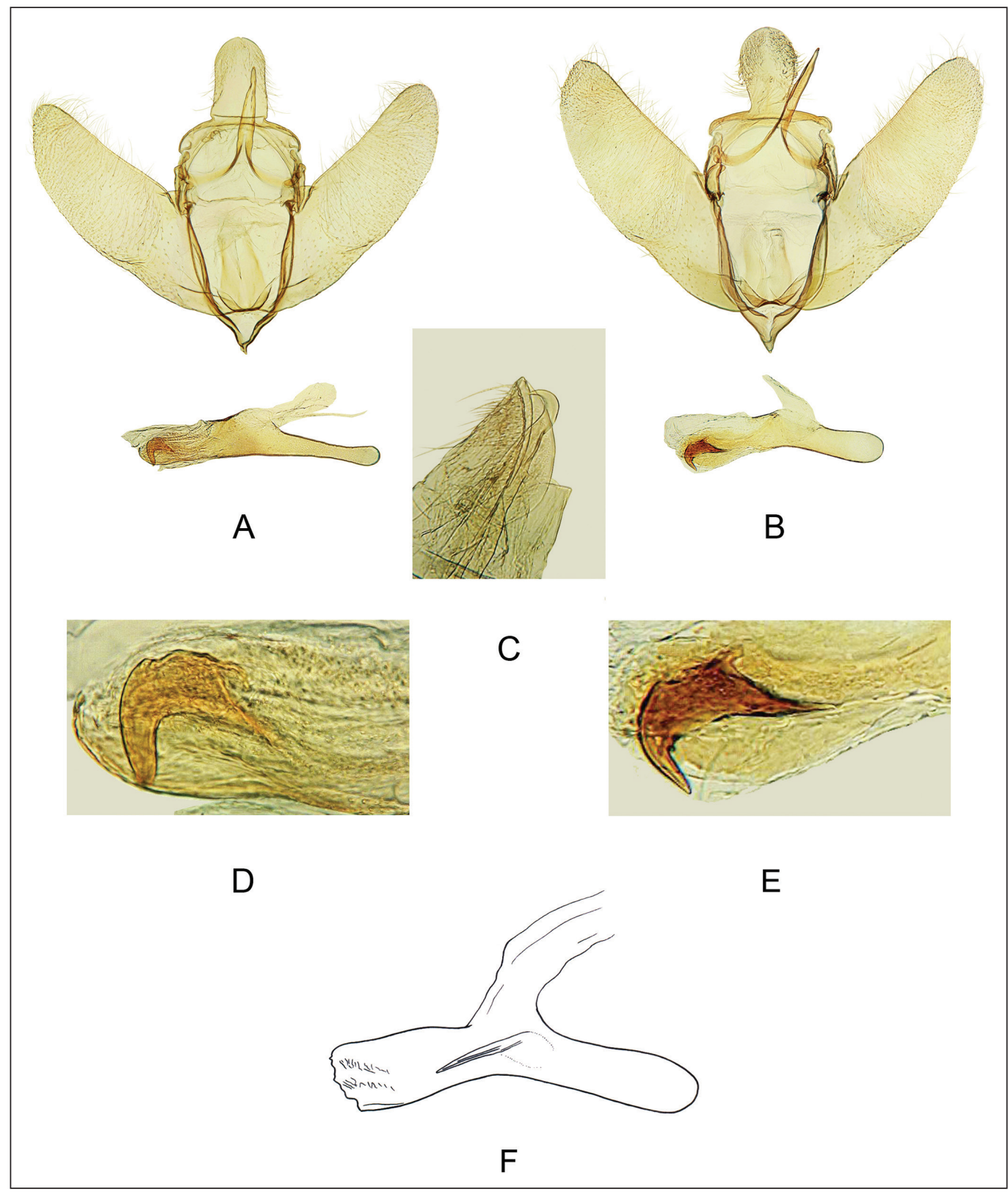

Figure 2. Male genitalia in A. gambronensis sp. n. (A, D) and A. kurdistanella Amsel (B, C, E), and phallus in S. robustus $(\mathbf{F})$. A, B) main armature and phallus, C) distal part of uncus and gnathos in lateral view, D, E) distal part of phallus in lateral view, showing cornutus.

dorsally, and ciliated ventrally. In male, each flagellum with a transverse row of at least ten long ciliae ventrally, the lateral ciliae the longest, length of the longest cilia almost two times the width of shaft (Figs 4C, E); in female each with a row of several short ventral ciliae (length of cilia less 
that the width of the shaft). Length of the antennae slightly more than half length of the forewing. Thorax, tegulae, and abdomen covered with yellowish-creamy and creamy scales, respectively.

Forewing (Fig. 1C) an elongated triangle, ground colour pale-ochreous to yellowish-ochre with two white antemedian and postmedian transverse lines, the antemedian line from the base at slightly beyond one-fifth of the forewing length, edged with darker scales externally, and straight to slightly convex medially, postmedian line from the base to slightly behind four-fifth of the forewing length, edged with darker scales internally, slightly convexed near to costal margin and then slightly concaved at two-thirds of its length from costal margin. The area between the two transverse lines slightly darker than the ground colour, and without discocellular stigma. Costal margin from the base to postmedian line with nine narrow, brown longitudinal stripes with different length at the upper as well as at the underside, alternating with short white stripes. Fringes creamy-white with some scattered pale-ochreous scales. Hindwing (Fig. 1C) creamy-white with some scattered light-brown scales concentrated in the middle part and absent both at costal and internal margins, and some scattered light-brown scales at the internal margin of termen. In some species these scales are hardly visible. Fringes in the same colour as the hindwing. Underside of the both fore- and hindwing yellowish-creamy, but in the forewing with scattered pale-ochreous scales and some pale-ochreous ones at the area of postmedian line, close to the costal margin.

Male genitalia (Figs 2A, D) $(n=1)$. Uncus rectangular and apically rounded, with the same width throughout the length; free end of gnathos lanceolate, apically without clear hook; tegumen relatively wide, its width two times the width of uncus; valva nearly straight, slightly narrowed distally, proximal end of valva at costal margin with a small semicircular plate; sacculus prominent; width of juxta slightly decreasing distally; vinculum almost triangular with pointed tip; phallus cleaver-shaped, width of the basal half nearly half length of distal half, slightly shorter than the length of valva, with orifice of vesica positioned mid-ventrally, cornutus as an asymmetrical anchor-shaped sclerotized structure, and some minute spines arranged distally.

Female genitalia (Figs 3A, C) $(n=2)$. Papillae anales almost semi-ovoid with rounded tip, covered with both short and relatively long hairs; apophyses posteriores very long, 2.77-2.85 times the length of apophyses anteriores, and slightly narrowed posteriorly, apophyses anteriores slightly thicker than apophyses posteriores and slightly curved posteriorly; ostium bursae very small and rounded, positioned at the bottom of a cavity produced by membranous area between eighth and seventh abdominal sternite; antrum membranous, short and tube-shaped, surrounded by folded walls on lateral sides. The folded area clearly extended to the posterior end of ductus bursae; colliculum absent; ductus bursae relatively wide, bulbous near the junction with antrum, with an almost knee-shaped bend at this area; ductus seminalis originates from the bulbous area of ductus bursae in the back (Figs 3A, C); border of ductus bursae and corpus bursae more or less indistinguishable; corpus bursae pear-shaped and without signum; eighth abdominal tergite with a distinct triangular plate in the middle; length of the seventh abdominal segment almost twice the eighth segment.

Distribution. Iran: Hormozgan Province (Isin).

Etymology. Isin (the type locality of the new species) is a rural district in the central district of Bandar Abbas County, Hormozgan Province, and this species is named according to the old name of Bandar Abbas, i.e. "Gambron".

Biology. Unknown. 


\section{Acteniopsis kurdistanella Amsel, 1959}

Material examined. Iran, Ardebil Prov.: 1 ở, Khalkhāl, Hashtchin- Khalkhāl Rd., N37²26'54.5”, E04854'50.6”, 837 m, 16.VII.2013, Afsariān, Sarafrāzi leg.; Chāhārmahāl va Bakhtiāri Prov.: 1 đ 1 \&, Chelgerd, 2500 m, 17, 18.VIII.1995,

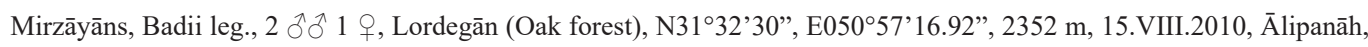
Nematiān leg.; Fārs Prov.: 1 đ̃, Sepidān, Mārgoon waterfall, 1910 m, 28.IX.1996, Barāri, Parchami-Arāghi, Moghaddam leg., 1 †, Kāmfiruz, Tang-e Bostānak, 1730-1900 m, 17.VIII.2000, Badii, Moghaddam, Mofidi-Neyestānak leg.;

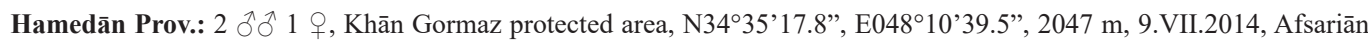
leg.; Hormozgān Prov.: 1 đ̃ , Bandar Abbās, Kahurestān, 17.III.1971, 15 m, Āyatollāhi, Pāzuki leg.; Kermānshāh Prov.: 1 ㅇ, Chalabeh, Bisotun, N34²2'57.2”, E4716’38.7”, 1652 m, 12.VII.2014, Afsariān leg.; Kohgiluyeh va Boyerahmad Prov.: 2 đ̊ đ̊, Tang-e Meymand, 1650 m, 9.IX.1971, Ebrāhimi, Badii leg.; Kordestān Prov.: Marivān, 26.VI.2004, Mansurghāzi leg.; Markazi Prov.: 1 đ̃, Salafchegān, Dizijān, 1550 m, 29.VII.1997, Barāri, Mofidi-Neyestānak leg.; Zanjān Prov.: 1 ổ, Zanjān, Ābbar, N3656’19.2”, E4859’32 89”, 1156 m, 21.VII.2010, Ālipanāh leg. (GS: HA-2308, HA-2310).

Remarks. Acteniopsis kurdistanella was described by Amsel (1959) based on one male and two females collected in Iraq (Haji Omran). However the female was not sufficiently described and no information was presented for the female genitalia by Amsel (1959). Later, a new form of this species, A. kurdistanella f. unicolorella was presented by Amsel (1961), only based on one male specimen. We found five females mostly with the same collecting data as the males and similar wing patterns among the specimens preserved in HMIM. The female specimen is here redescribed and illustrated.

Diagnosis. The female genitalia of this species is very close to that of $A$. gambronensis, and their main differences are in the width of ductus bursae and shape of the posterior end of ductus bursae (see diagnosis of A. gambronensis).

Redescription of the female. Forewing length $\bar{x}=8.62 \mathrm{~mm} \pm 0.67(\mathrm{n}=5)$; fore- and hindwing (Fig. 1D) similar to those of the male in shape, ground colour and pattern (see Amsel 1959). Head, Chaetosemata and ocelli present; frons smooth; frons and vertex covered with creamy-white scales; occipital area roofed with slightly appressed creamy-white scales; collar covered with creamywhite to pale-ochreous scales; labial palpi porrect with slightly drooping apex, its length 1.82-1.87 times the horizontal diameter of compound eye, second segment the longest, first segment almost half length or slightly less than half length of the second one and apical segment very short, slightly less than one-fifth of the second segment. Labial palpi covered with ochre to pale brown scales tinged with reddish-brown scales latero-ventrally, except for distal one-fifth (or slightly less than this) which is white dorso-laterally, all the segments white internally except for the ventral margin of the first and second segment which are slightly darker; maxillary palpi short (slightly more than one-fourth of the length of labial palpi), covered with pale-ochreous scales laterally; proboscis covered with ochreous-creamy scales basally with few scattered reddish-brown scales; antennae annulated with light brown and creamy scales dorsally, and shortly ciliated ventrally, each flagellum with several short ciliae (length of cilia less that the width of the shaft), Length of the antennae slightly more than half length of the forewing. Thorax and tegulae, and abdomen in the same colour as the forewing ground colour.

Female genitalia (Figs 3B, D) $(n=1)$. Papillae anales almost semi-ovoid with rounded tip, covered with both short and relatively long hairs; apophyses posteriores very long, 2.7 times the length of apophyses anteriores, and slightly narrowed posteriorly, apophyses anteriores slightly thicker 


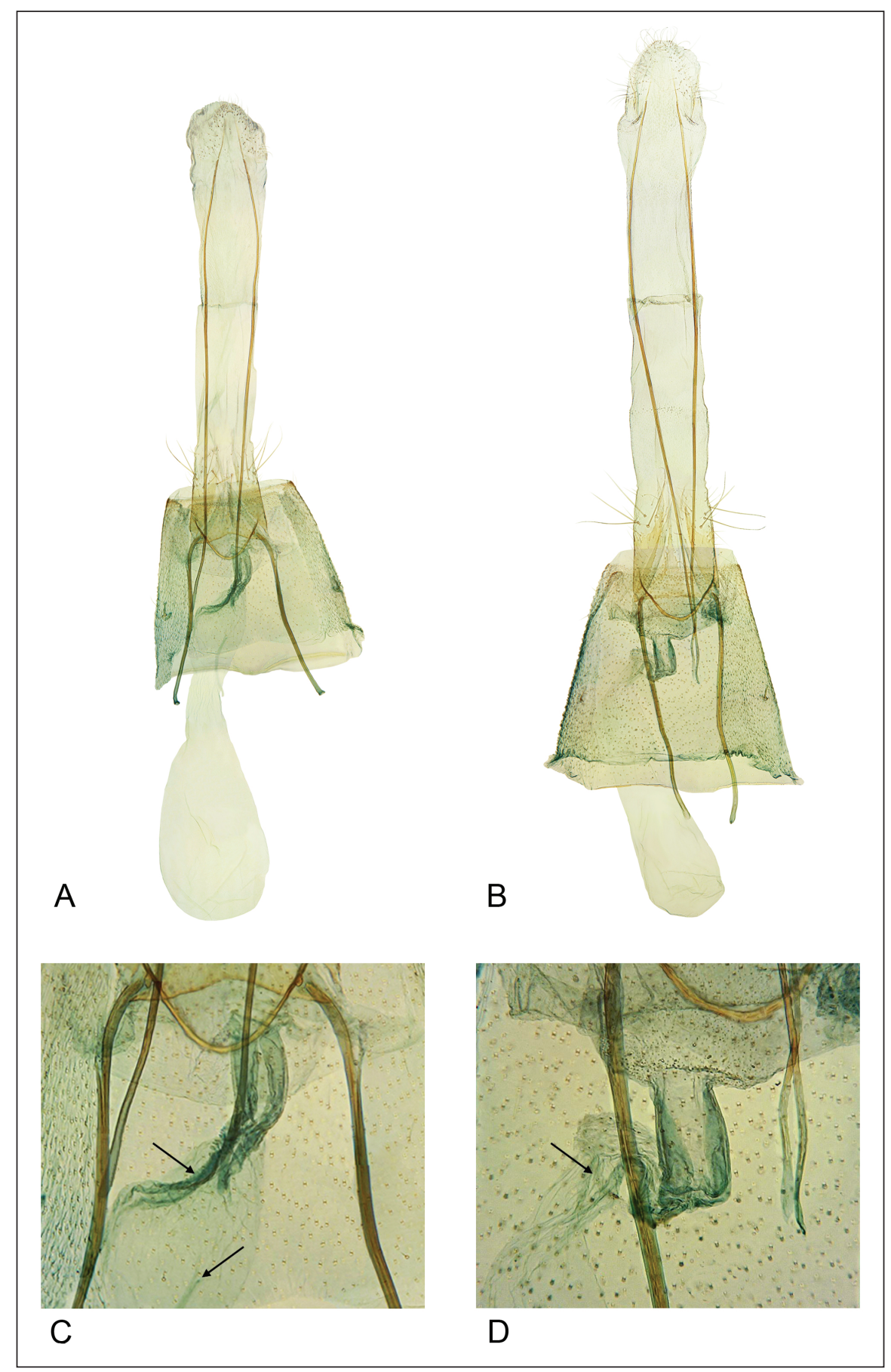

Figure 3. Female genitalia in A. gambronensis sp. n. (A, C) and A. kurdistanella Amsel (B, D). A, B) genitalia in ventral view, $\mathbf{C}, \mathbf{D})$ middle part of genitalia. Upper and lower arrows in figure $\mathrm{C}$ indicate the folded area at the anterior end of ductus bursae and locus of origin of the ductus seminalis, respectively and in figure $\mathrm{D}$ indicates the locus of origin of the ductus seminalis. 


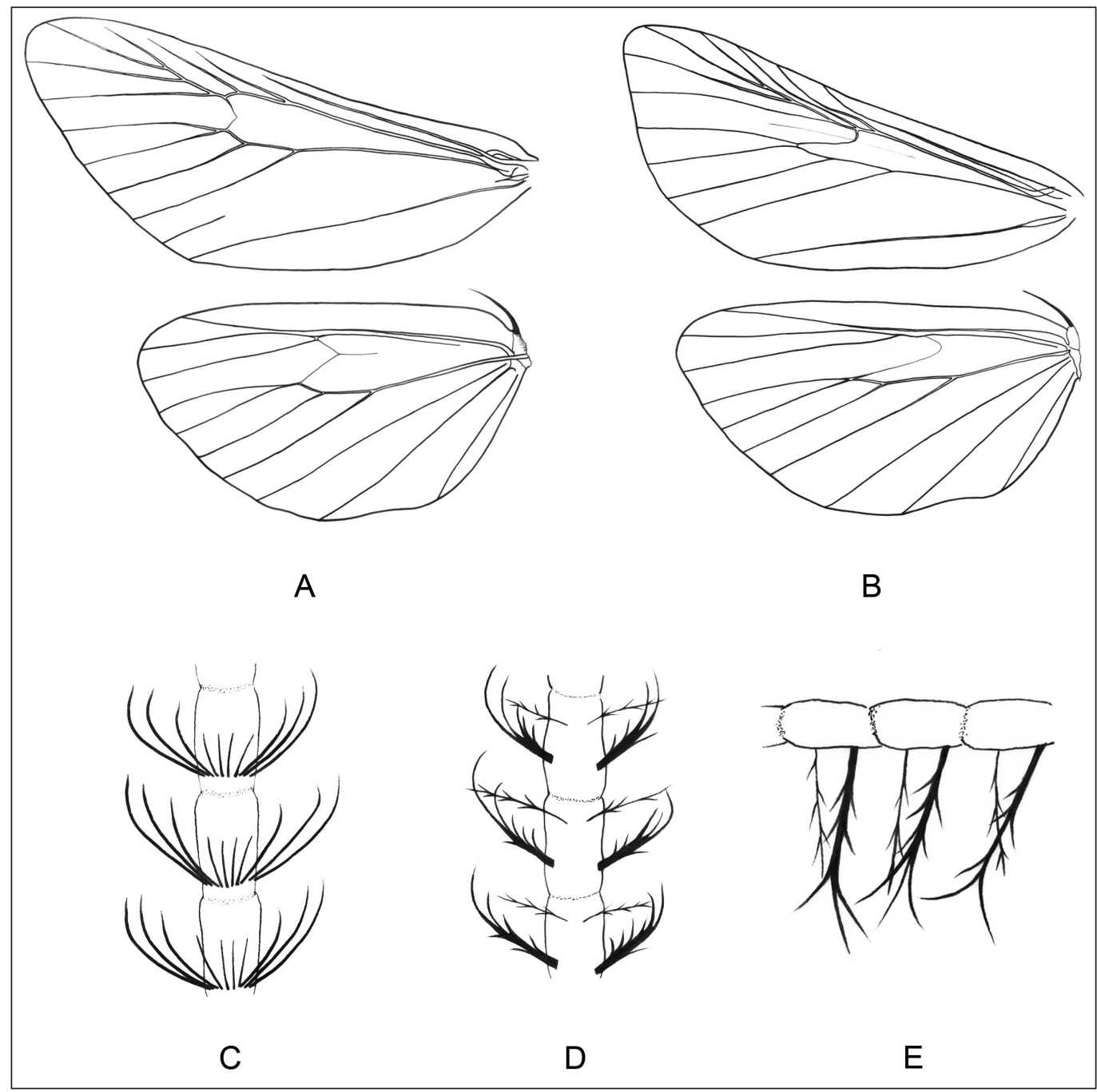

Figure 4. Wings venation $(\mathbf{A}, \mathbf{B})$ in $A$. kurdistanella $(\mathbf{A})$ and $S$. brunnealis $(\mathbf{B})$, and stylized drawings of ventral ciliae of the antennae $(\mathbf{C}-\mathbf{E})$ in $A$. gambronensis sp. n. $(\mathbf{C})$ and $S$. brunnealis $(\mathbf{D}, \mathbf{E}) . \mathbf{C}, \mathbf{D})$ in ventral view, E) in lateral view, showing ciliae of the left part.

than apophyses posteriores and slightly curved posteriorly; ostium bursae very small and rounded, positioned at the bottom of a cavity produced by membranous area between eighth and seventh abdominal sternite; antrum membranous, short and tube-shaped, surrounded by folded walls on lateral sides. The folded area slightly extended to the posterior end of ductus bursae; colliculum absent; ductus bursae slightly narrowed posteriorly at the junction with antrum and with upturned bending at this area; ductus seminalis arisen from the upturned area of ductus bursae in the back (Figs 3B, D); the border of ductus bursae and corpus bursae indistinguishable; corpus bursae elongated tear-shaped, without signum; eighth abdominal tergite with a distinct triangular plate in the middle; length of seventh abdominal segment almost twice length of eighth segment. 
Distribution. Iraq (Haji Omran; the type locality); Iran (Saadatabad, Sine Sefid, Mian Kotal, Komehr, Karaj, Sultanabad) (Amsel 1961).

Additional notes. A new form of A. kurdistanella, i.e. A. kurdistanella f. unicolorella Amsel, 1961 was presented by Amsel based on one male specimen collected in Sultanabad. As stated by this author, it was similar to the nominative form in the genitalia and all other characteristics except for the wings which were without any markings. In all the examined specimens, both fore- and hindwing patterns were the same and few specimens were slightly darker. It seems that the maintenance of two subspecies for this species would not be logical, but since we don't have the type specimens a decision about the validity of a subspecies remains to be postponed.

In the original description of Amsel (1959), no mention is made about the arrangement of ventral ciliae of the male antennae. As we have shown in the present study, the arrangement of the male antennal ciliae in this species is similar to that of $A$. gambronensis: each segment has a transverse row of at least ten ciliae ventrally, with the lateral segments the longest, whilst the length of the longest ciliae is almost twice the width of shaft. Sometimes it seems that the two outermost lateral ciliae originate from a common point. According to Amsel (1959), the uncus of A. kurdistanella has parallel margins, but examination of the Iranian species has shown that the uncus is slightly constricted basally (Fig. 2B).

Discussion. As mentioned above, the two genera Acteniopsis and Stemmatophora have some differences in wing venations and ciliae on the ventral surface of the antennae; however our findings are somewhat different from those given by Amsel (1959). As we observed, in the forewing of males and females of both A. kurdistanella and A. gambronensis, like in the Stemmatophora species, vein $\mathrm{R}_{5}$ is stalked with $\mathrm{R}_{3}+\mathrm{R}_{4}$ (Figs $4 \mathrm{~A}, \mathrm{~B}$ ). The length of the common stalk of $\mathrm{R}_{5}$ with $\mathrm{R}_{3}+\mathrm{R}_{4}$ in A. gambronensis is slightly shorter than in A. kurdistanella and in the latter species it is slightly shorter than in S. brunnealis. Moreover, based on Amsel (1959), in the hindwing of Acteniopsis the veins $\mathrm{M}_{2}$ and $\mathrm{M}_{3}$ originate from a common point, while in Stemmatophora these are on a short stalk. As we have shown, in the hindwing of $A$. gambronensis the veins $\mathrm{M}_{2}$ and $\mathrm{M}_{3}$ originate from one point, in S. brunnealis they are on a very short stalk. (Fig. 4B), and only in A. kurdistanella they are clearly stalked (Fig. 4A). Therefore, these characters cannot be considered as reliable diagnostic to distinguish Acteniopsis from Stemmatophora.

Furthermore, based on the present study, the structure of the ventral ciliae of the male antennae in these two genera is completely different. In Stemmatophora each flagellum has two pairs of plumose ciliae, one pair at the proximal end of the flagellum which is larger and longer, and another pair beyond it, at the medial part of the segment and slightly positioned interiorly compared with the first pair which is smaller and shorter (Figs 4D, E). In Acteniopsis, each flagellum has a transverse row of at least ten simple ciliae in which the lateral ciliae are the longest and slightly curved inward, whilst the medial ones are straight and about half as long as the lateral ciliae (Fig. 4C).

Based on the present study, the genus Acteniopsis is represented by two species worldwide that can easily be distinguished from each other based on their forewing pattern and shape of the phallus (see diagnosis of $A$. gambronensis). One of these two species has been described from Iraq and later form Iran, and another one is described from Iran. It seems that the genus is restricted to Saharo-Arabian and Irano-Turanian zoogeographical regions and it is most probable that these areas could be considered as its origin centre. Owing to the insufficient sampling in different parts of Iran, the presence of $A$. kurdistanella in some other parts of the country could be possible; this is also applicable for $A$. gambronensis along the southern borders of Iran. 


\section{Acknowledgements}

We wish to express our gratitude to Dr. Hugo van der Wolf (Nuenen, Netherlands) and Dr. Shahab Manzari (IRIPP, Tehran, Iran) for editing the manuscript linguistically and to an anonymous referee.

\section{References}

Amsel HG (1959) Irakische Kleinschmetterlinge, 2. Bulletin de la Société Entomologique d’Égypte 43: 41-83. Amsel HG (1961) Die Microlepidopteren der Brandt'schen Iran-Ausbeute. 5. Teil. Arkiv för Zoologie (ser. 2) 13(17): 323-445. [pls. 1-9]

Asselbergs J (2010) Order Lepidoptera, superfamily Pyraloidea (part 2). In: van Harten A (Ed.) Arthropod Fauna of the UAE 2: 554-563.

Clarke JFG (1941) The preparation of slides of the genitalia of Lepidoptera. Bulletin of the Brooklyn Entomological Society 36: 149-161.

Munroe E, Solis MA (1999) The Pyraloidea. In: Kristensen NP (Ed.) Handbook of Zoology, Vol. IV: Arthropoda: Insecta (Part 35: Lepidoptera, Moths and Butterflies, Volume 1: Evolution, Systematics, and Biogeography. Walter de Guyter, Berlin, New York, 233-256.

Nuss M, Landry B, Vegliante F, Tränkner A, Mally R, Hayden J, Segerer A, Li H, Schouten R, Solis MA, Trofimova T, De Prins J, Speidel W (2003-2017) Global Information System on Pyraloidea. Available from http://www.pyraloidea.org [accessed: February $4^{\text {th }}, 2017$ ]

Robinson GS (1976) The preparation of slides of Lepidoptera genitalia with special reference to the Microlepidoptera. Entomologist's Gazette 27: 127-132.

Solis MA, Shaffer M (1999) Contribution towards the study of the Pyralinae (Pyralidae): Historical review, morphology, and nomenclature. Journal of Lepidopterist's Society 53(1): 1-10. 